\title{
LA PARTICIPACIÓN DE LA MUJER EN LA FUNCIÓN NOTARIAL: NOTARIA O NOTARIO/LENGUAJE INCLUYENTE ${ }^{1}$
}

\section{María inés Aragón Salcido}

Sumario: Introducción. II. Revisión de diversos instrumentos jurídicos en materia de género. III. Conclusiones.IV. Bibliografía

\section{Resumen}

Por medio del examen de la Jurisprudencia, los derechos humanos incorporados en nuestra Carta Magna Nacional y sus homólogas de las entidades federartivas, la legislación nacional y local del Estado de Sonora y ciertas obras nacionales y extranjeras relacionadas con el tema de género, se concluye que es urgente la intervención del notariado mexicano para plantear ante los congresos locales la necesidad de armonizar la legislación correspondiente para incorporar la perspectiva de género, utilizar un lenguaje incluyente y visibilizar a las mujeres en la función notarial en nuestro país.

Palabras clave: lenguaje incluyente,función notaral

\section{WOMEN'S PARTICIPATION IN THE NOTARIAL FUNCTION: NOTARY OR NOTARY / INCLUSIVE LANGUAGE}

\section{Abstract}

Through the examination of Jurisprudence, human rights incorporated in our National Constitution and their counterparts of the federative entities, the national and local legislation as the Sonora State and certain national and foreign works related to the gender issue, it is concluded that it is urgent the intervention of the Mexican notarial guildin order to demand the intervention of the local congresses on harmonization of the corresponding legislation, to incorporate the gender perspective, to use an inclusive language and to make women visible in the notarial function in our country.

Keywords :inclusive language, notarial function

\footnotetext{
${ }^{1}$ Ponencia presentada en el X Congreso Internacional de derecho Administrativo y VIII Congreso Mexicano de Derecho Administrativo, Sede: Universidad de Guanajuato, 6 y 7 diciembre de 2018

${ }^{2}$ Notaria Pública Número 66,con licencia,Doctora, docente e investigadora de asignatura del Instituto Sonorense de Administración Pública. ISAPAC
} 


\section{Introducción}

El mes de octubre nos evoca la conmemoración del derecho al voto de la mujer en México que se logró hace 65 años, en 1953. Como sabemos, la lucha por los derechos políticos de las mujeres no ha sido fácil y en muchas ocasiones ha avanzado a golpe de sentencias, ${ }^{3}$ gracias a lo cual se ha logrado instituir la paridad de género en la Constitución Federal y en la legislación mexicana, hasta que alcancemos la igualdad sustantiva: la igualdad en los hechos.

En este contexto, resulta importante destacar el tema de la participación de las mujeres en la función notarial, históricamente en la que "...se advierte la ausencia de los principios de igualdad y no discriminación, lo que ha limitado el acceso de las mujeres para ocupar la titularidad notarial en un plano de igualdad". ${ }^{4}$

\section{Revisión de diversos instrumentos jurídicos y literatura sobre} género

De ahí la necesidad de revisar los antecedentes históricos en el tema notarial, y al respecto encontramos la sentencia en el amparo administrativo en revisión, número 7010, del año 1942, Sección $2^{\text {a }}$, bajo el rubro NOTARIOS, LAS ABOGADAS PUEDEN SER ASPIRANTES, en el que se decidió a grandes rasgos lo siguiente: el amparo se interpuso por ANGELINA DOMERQ BALSECA, en contra de la resolución del Jefe de Departamento del Distrito Federal en respuesta a la solicitud de información que hiciera el encargado de la notaría sobre la práctica de aspirante a notario que pretendía realizar ANGELINA DOMERQ

\footnotetext{
${ }^{3}$ Alanis, María del Carmen, "Paridad a golpe de sentencias: “\#MujeresAVotar", El Universal, 07 de junio 2015[on line]disponible en:

http://www.eluniversal.com.mx/entrada-de-opinion/articulo/maria-del-carmenalanis/nacion/politica/2015/06/7/paridad-golpe-de.

${ }^{4}$ Centro de Estudios para el Adelanto de las Mujeres y la Equidad de Género, Fedatarios Públicos con Perspectiva de Género (Notarios Públicos), Cámara de Diputados, LXIII Legislatura, abril 2017,p22[on line]Disponible en: http://www3.diputados.gob.mx/camara/content/download/335207/1195756/file/FED ATARIOS\%20P\%C3\%9ABLICOS\%20CON\%20PEG.pdf.
} 
BIOLEX Revista Jurídica del Departamento de Derecho UNISON URC

BALSECA; le respondieron que no puede aprovecharle para los efectos del artículo 24 de la Ley del Notariado, por faltar a la susodicha quejosa el requisito de la ciudadanía (artículo 35, fracciones I y II), es decir, por razón de sexo, no tenía las prerrogativas relativas a la ciudadanía, de votar y ser votada, violentándose los artículo 4, 14 y 16 constitucionales, porque le impedían aspirar al empleo en su profesión de notario, otorgándole la Justicia de la Unión el amparo y protección a Angelina Domerq Balseca. ${ }^{5}$

5 "Si la quejosa se presentó en una notaría, por tener el título de licenciada en derecho, para hacer su práctica de notario, y el encargado de esa notaría, elevó escrito al jefe del Departamento Central responsable comunicándole que la aludida quejosa iniciaba su práctica de aspirante, a lo que se contestó que tal práctica no podría aprovecharle, apoyándose esta decisión en la fracción II del artículo 24, de la Ley del Notariado, que exige que los aspirantes deberán ser mexicanos, tener veinticinco años cumplidos, estar en el ejercicio de sus derechos de ciudadano y no pertenecer al estado eclesiástico, por faltar a la susodicha quejosa el requisito relativo a la ciudadanía, porque el artículo 35 constitucional, (fracciones I y II), señala como prerrogativas del ciudadano las de votar en las elecciones populares y de poder ser votado para todos los cargos de elección popular y nombrado para cualquier otro cargo o comisión, teniendo las cualidades que establezca la ley, derechos que no tiene la agraviada por razón de su sexo, debe decirse que si se toma en cuenta que las responsables no señalaron disposición alguna que funde la excepción que alegan respecto de las personas del sexo femenino y que el espíritu del artículo 24 , de la Ley del Notariado no es otro que el de exigir que el aspirante no haya sido suspendido o privado de sus derechos de ciudadanía, atento el requisito de honestidad plena, buena conducta y antecedentes que se requieren para el desempeño de estos cargos, el acto reclamado es violatorio de los artículos 4o., 14 y 16 de la Constitución Federal, porque impide a la quejosa aspirar al empleo en su profesión de notario, sin razón legal para ello, porque la priva de derechos que la ley le confiere, sin previo juicio, y porque le infiere molestias infundadas e inmotivadas, debiéndose otorgarle el amparo de la Justicia Federal". Amparo administrativo en revisión 7010/43. Domerq Balseca Angelina. 6 de marzo de 1944. Mayoría de tres votos. Disidentes: Gabino Fraga y Manuel Bartlett Bautista. Semanario Judicial de la Federación, tesis 324044.

Web. https://sjf.scjn.gob.mx/SJFSist/Paginas/DetalleGeneralV2.aspx?Epoca=1e3e1fdfdf 8fcfd\&Apendice=1fffdfffcfcff\&Expresion=\&Dominio=Rubro,Texto,Precedentes, Loca lizacion\&TA_TJ=\&Orden=1\&Clase=DetalleTesisBL\&NumTE=14\&Epp=20\&Desde $=$ $-100 \&$ Hasta $=-$ 100\&Index=0\&InstanciasSeleccionadas $=6,1,2,3,4,5,50,7 \& I D=324044 \&$ Hit=13\&IDs $=2001101,2001102,160361,162824,162823,170783,170721,173575,177936,1807$ 
El antecedente citado, podemos decir, es la motivación de la Ley del Notariado para el Distrito Federal, publicada en el Diario Oficial de la Federación de fecha 23 de febrero de 1946, en la cual destaca la redacción del artículo primero, el cual estableció: "Define al notario, diciendo que es la persona, varón o mujer, investida de fe pública para hacer constar los actos o hechos jurídicos revistiéndolos de solemnidad y forma legales". ${ }^{6}$ Así, se vino a establecer que las mujeres sí podían ejercer la función notarial. La citada ley de avanzad que diferenciaba los géneros en la profesión notarial, tuvo una vigencia de treinta años; en 1979 se expide una nueva Ley que se publicó en Diario Oficial de la Federación el 08 de enero de 1980 y se abrogó con la Ley del Notariado que se publicó el 28 de marzo del 2000, suprimiéndose en ambas leyes el avance de diferenciar los géneros en la definición de notario público, identificando el concepto "con el género gramatical masculino como universal para referirse a la totalidad de las personas, con lo que se incurre en el error de reforzar la asociación del 'todo' con los hombres", ${ }^{7}$ lo que se ha venido justificando por el principio de economía lingüística por sobre el criterio de la pragmática que se da en la dinámica de los cargos y profesiones cuando se ocupan por hombres y mujeres, esto es: notario público, significa que el concepto comprende tanto a mujeres como hombres, según una visión tradicional del gremio notarial, que en algunos casos en la práctica notarial se asienta en la actuación de las mujeres notarias públicas, YO, EL NOTARIO DOY FE.

Al respecto, el Manual del Español Urgente, de la agencia EFE, desde 1985 establece: "Conviene generalizar el femenino a los nombres de las profesiones 0 cargos cuando estos son desempeñados por mujeres", ${ }^{8}$ redacción que se

05,191977,214820,324044,810922\&tipoTesis=\&Semanario=0\&tabla=\&Referencia $=$ THE_TESIS\&Tema=693.

${ }^{6}$ Froylán Bañuelos Sánchez, Derecho Notarial, p.p. 71 y 72.

${ }^{7}$ Conapred, 10 Recomendaciones para el uso no sexista del lenguaje, p. 11.

${ }^{8}$ López de la Vieja, María Teresa (ed.), Feminismo: del pasado al presente, Salamanca, Universidad de Salamanca, 2000,p41 
mantiene en la edición actual del año 2017. En el Diccionario Panhispánico de Dudas de la RAE (Real Academia Española), actualmente, en el apartado del género gramatical, aunque con reservas lingüísticas, se puede leer en su más reciente edición en línea lo siguiente: “...en los últimos tiempos, por razones de corrección política, que no de corrección lingüística, se está extendiendo la costumbre de hacer explícita en estos casos la alusión a ambos sexos... Solo cuando la oposición de sexos es un factor relevante en el contexto, es necesaria la presencia explícita de ambos géneros", ${ }^{9}$ a pesar de que hace cinco años este tipo de reconocimiento al lenguaje con perspectiva de género era impensable en el seno de la RAE. De igual forma, la lingüista Judith González Ferrán, quien es jefa de proyecto del Manual de Estilo para Internet de Fundéu BBVA (fundación que es asesorada por los miembros de la RAE a través de la página de Internet del Español Urgente, la cual es la web más actualizada en materia de normas y novedades del español), escribió lo siguiente acerca de la utilización de los cargos y profesiones en femenino: "Pues yo soy filóloga y desde la Fundación del Español Urgente trabajamos por ofrecer una forma en femenino, una alternativa válida para quien la quiera porque creemos que es tarea de todos normalizar estos términos, usándolos con confianza en la lengua y con respeto por las personas que hay detrás (...) Nombrar a las mujeres con las formas masculinas de las profesiones y cargos configura en la mente del receptor un panorama que no siempre es el más ajustado a la realidad". ${ }^{10}$

La nueva Ley del Notariado para la Ciudad de México ${ }^{11}$, que entró en vigor al día siguiente de la adopción de la Constitución Política de la Ciudad de México,

9 Real Academia Española, Género, octubre 2018, web. http://lema.rae.es/dpd/srv/search?id=Tr5x8MFOuD6DVTIDBg.

${ }^{10}$ González Ferrán, Judith «Profesora», «médica», «jueza», "pilota»..., profesiones en femenino, Fundéu BBVA, octubre 2018, web. https://www.fundeu.es/noticia/profesora-medica-jueza-pilota-profesiones-enfemenino/.

${ }^{11}$ Gaceta Oficial de la Ciudad de México, vigésima época, número1, 5 de febrero de 2017, web, octubre 2018-12-13 [en línea]Disponible en: 
la cual inició su vigencia el día 18 de septiembre de 2018, no contempla el lenguaje incluyente y sigue utilizando en todo su articulado el concepto de notario. Es decir, continúa con la concepción masculinizada de la función notarial.

En el Estado de Sonora, con fecha 24 de mayo de 1961, de conformidad con el artículo 12 de la Ley del Notariado para el Estado de Sonora de 1902, presentó su examen y protestó como notario público número 59 , con residencia en Ciudad Obregón, Sonora, la licenciada en derecho MARÍA JOSEFINA PÉREZ CONTRERAS, quien fue una alumna brillante de la Escuela de Derecho de la Universidad de Sonora y que actualmente tiene 57 años ejerciendo la función notarial, con honestidad y distingue al gremio notarial con su desempeño. Ella, a la vez, fue la primera mujer magistrada Presidenta del Supremo Tribunal de Justicia del Estado de Sonora.

Es un verdadero hallazgo, no solo a nivel local, sino incluso del Distrito Federal, pues este tuvo su primera mujer notaria en el año de 1984, en la persona de la licenciada Olga María del Carmen Sánchez Cordero, por lo que se antoja interesante rescatar, en cada entidad federativa, la fecha en que las mujeres accedieron por primera vez a la función notarial.

Comparando la participación de las mujeres en la función notarial con los cargos de toma de decisiones y de elección popular, encontramos que en el periodo de 1937-1939 se consigna por primera vez la participación de una mujer en el gabinete del poder Ejecutivo del Estado de Sonora, la profesora Rosario Paliza Vda. de Carpio, como Directora de Educación Pública, sin tener aún reconocidos sus derechos políticos para votar y ser votada. Veintiún años

https://www.cdmx.gob.mx/storage/app/uploads/public/59a/588/5d9/59a5885d9b2c 7133832865.pdf. 
después, en 1960, la profesora Guadalupe Ortega de Arvizu ocupó la misma responsabilidad en el sector educativo. ${ }^{12}$

Después del derecho al voto a la mujer en 1953, en el periodo de 19551958, tuvimos en Sonora a la primera diputada, María de Jesús Guirado Ibarra, procedente del sector obrero ${ }^{13}$; en el periodo 1961-1964 Alicia Arellano Tapia ocupó el cargo de diputada federal; en 1964 aparecen las primeras senadoras en el país: María Lavalle Urbina (Campeche) y Alicia Arellano Tapia (Sonora); asimismo, fue en 1973 cuando se tuvo la primera Presidenta Municipal en Magdalena: Alicia Arellano Tapia. ${ }^{14}$ En 2015, por primera vez se elige a una mujer como Gobernadora del Estado de Sonora, la licenciada Claudia Artemiza Pavlovich Arellano. Actualmente, gracias a la paridad de género en las candidaturas a los cargos de diputaciones y planillas de Ayuntamientos, hay en nuestro Congreso del Estado de Sonora 14 mujeres y en presidencias municipales 26 mujeres, que representan el $42 \%$ y el $37 \%$, respectivamente.

La ocasión es propicia para reflexionar sobre la legislación notarial en nuestro país, la cual a partir de la reforma constitucional del artículo $1^{\circ}$ que prohíbe la discriminación motivada (entre otras) por el género, y los tratados y convenciones internacionales, son fundamentos esenciales a la hora de trazar la ruta hacia la conformación de un estado de derecho y a una cultura de la inclusión. Las leyes para la Igualdad entre Hombres y Mujeres en nuestro país, dentro de sus objetivos destacan la eliminación de los estereotipos establecidos en función del sexo y la utilización de un lenguaje no sexista en el ámbito administrativo y su fomento en la totalidad de las relaciones sociales, promoviendo la utilización de un lenguaje con perspectiva de género.

\footnotetext{
${ }^{12}$ Aragón Salcido, María Inés, La participación política de la mujer en el estado de Sonora, Hermosillo, Instituto Sonorense de Administración Pública, ISAP A.C., 1997, p. 36.

13 Ibídem, p. 12.

14 Ibídem, p. 26.
} 
En este sentido, es pertinente reseñar la investigación que realizó el Centro De Estudios Para el Adelanto de las Mujeres y la Equidad de Género: Fedatarios Públicos con Perspectiva de Género (Notarios Públicos), en la cual se investigó la legislación de las entidades federativas y se tomaron en cuenta cuatro parámetros:

1) Requisitos para solicitar el examen de aspirante a notario.

2) Requisitos que deberá contener la convocatoria para presentar el examen de oposición los aspirantes al ejercicio del notariado.

3) Reglas para obtener la patente de aspirante y la de notario.

4) Reglas del examen para obtener la patente de notario, con el fin de "... visibilizar la falta de incorporación de la perspectiva de género y de las asimetrías legales". ${ }^{15} \mathrm{Y}$, en la que se concluye que: “...ninguna de las legislaciones cuenta con perspectiva de igualdad de género, se encuentran redactadas bajo un lenguaje sexista que invisibiliza a las mujeres" ${ }^{\prime 16}$; toda la redacción está en sentido masculino, sin incluirse el término de "notaria".

\section{A manera de Conclusiones}

Si bien, la función notarial ha sido una labor masculinizada, es necesario recordar que la reforma constitucional del artículo $1^{\circ}$, antes citada que incorpora los principios de progresividad, interpretación conforme pro persona y el enfoque de derechos humanos, trae aparejada la obligación de armonizar el marco jurídico nacional. ${ }^{17}$

La tarea del notariado mexicano debe ser plantear ante los congresos locales la armonización de la legislación para incorporar la perspectiva de género,

${ }^{15}$ Centro de Estudios para el Adelanto de las Mujeres y la Equidad de Género, op. cit., p. 28.

${ }_{17}^{16}$ Ibidem, p. 84.

${ }^{17}$ Ibidem, p. 5. 
utilizar un lenguaje incluyente y visibilizar a las mujeres en la función notarial en nuestro país. Cabe destacar que la Ley del Notariado Plurinacional de Bolivia del año 2014, ya utiliza tanto los términos "notario" como "notaria", en todo el cuerpo normativo.

Si bien en 1944 se dio una sentencia que, con un enfoque de derechos humanos, sin explicitarlo así, establecía las bases para que las mujeres pudieran ser notarias, y la Ley del Notariado del Distrito Federal de 1945, que podríamos decir utilizó por primera vez un lenguaje incluyente; es en Sonora en 1961, en un hecho inédito, con una legislación conservadora, que se designa a una mujer como notario público.

En Sonora, aun antes de la reforma de los derechos políticos tuvimos a una mujer en el gabinete en la Dirección General de Educación en 1937; nueve años antes de la reforma de 1946 que permitió a las mujeres votar en las elecciones municipales y dieciséis años antes de que se reconocieran los derechos políticos para votar y ser votadas en todas las elecciones a las mujeres. En este contexto de avance paulatino atípico, tuvimos en Sonora a la primera notaria pública en 1961.

Como comentario final de esta narrativa, diría:

Yo, notaria pública, doy fe.

\section{BiBLIOGRAFÍA}

AlANIS, María del Carmen, "Paridad a golpe de sentencias: "\#MujeresAVotar", El Universal, 07 de junio 2015. Web. http://www.eluniversal.com.mx/entrada-deopinion/articulo/maria-del-carmen-alanis/nacion/politica/2015/06/7/paridad-golpe-de.

ARAGÓN SALCIDO, María Inés, La participación política de la mujer en el estado de Sonora, Hermosillo, Instituto Sonorense de Administración Pública, ISAP A.C., 1997.

BAÑUElos SÁNCHEZ, Froylán, Derecho Notarial, $3^{a}$ ed., México, Cárdenas Editor y Distribuidos, 1984. 
Centro de Estudios para el Adelanto de las Mujeres y la Equidad de GÉnERo, Fedatarios Públicos con Perspectiva de Género (Notarios Públicos), Cámara de Diputados, LXIII Legislatura, abril 2017, web. http://www3.diputados.gob.mx/camara/content/download/335207/1195756/file/FEDATARI OS\%20P\%C3\%9ABLICOS\%20CON\%20PEG.pdf.

CONAPRED, 10 Recomendaciones para el uso no sexista del lenguaje, $2^{a}$ ed., México, Textos Caracol número 1, 2009.

Gaceta Oficial de la Ciudad de México, vigésima época, número1, 5 de febrero de 2017, web, octubre 2018

https://www.cdmx.gob.mx/storage/app/uploads/public/59a/588/5d9/59a5885d9b2c713383 2865.pdf.

GONZÁLEZ FERRÁN, Judith, «Profesora», «médica», «jueza», «pilota»..., profesiones en femenino, Fundéu BBVA, octubre 2018, web.

https://www.fundeu.es/noticia/profesora-medica-jueza-pilota-profesiones-en-femenino/.

LÓPEZ DE LA VIEJA, María Teresa (ed.), Feminismo: del pasado al presente,

Salamanca, Universidad de Salamanca, 2000.

ReAl ACADEMIA ESPAÑOLA, Género, octubre 2018, web.

http://lema.rae.es/dpd/srv/search?id=Tr5x8MFOuD6DVTIDBg.

\section{JURISPRUDENCIA:}

Semanario Judicial de la Federación, Quinta época, instancia: Segunda Sala, tomo LXXIX, 6 de marzo de 1944, tesis 324044, amparo administrativo en revisión 7010/43, p. 4845, bajo el rubro: "NOTARIOS, LAS ABOGADAS PUEDEN SER ASPIRANTES A".

\section{LEGISLACIÓN CONSULTADA:}

Constitución Política de los Estados Unidos Mexicanos. Diario Oficial de la Federación, Ciudad de México, 10 de junio 2011.

Ley General para la Igualdad entre Mujeres y Hombres. Diario Oficial de la Federación, Ciudad de México, 2 de agosto 2006.

Ley del Notariado para el Estado de Sonora. Boletín Oficial del Estado de Sonora, Hermosillo, Sonora, 4 de enero de 1996.

Ley para la Igualdad entre Mujeres y Hombres en el Estado de Sonora. Boletín Oficial del Estado de Sonora, Hermosillo, Sonora, 25 de septiembre 2008.

Ley N 483, Ley del Notariado Plurinacional, La Paz, Bolivia, 25 de enero 2014

Recibido 8 diciembre 2018 Aceptado 10 Diciembre 2018 